\title{
Molecular weight of Nephila clavata spider silk
}

\author{
Takashi Matsuhira ${ }^{1}$ and Shigeyoshi Osaki ${ }^{2}$
}

The molecular weight of Nephila clavata spider silk was determined to be ca. $600 \mathrm{kDa}$, under unreduced conditions, corresponding to its natural state, using the sodium dodecyl sulfate polyacrylamide gel electrophoresis method and a protein marker with a maximum molecular weight of $500 \mathrm{kDa}$. The addition of 2-mercaptoethanol into the spider silk solution decreased the molecular weight from ca. $600 \mathrm{kDa}$ to ca. $270 \mathrm{kDa}$. Such a dramatic decrease in the molecular weight was ascribed to the presence of 2-mercaptoethanol as a reductant. This finding indicates the possibility that the reduction process cleaved the disulfide bonds formed between the spider silk proteins and then drastically decreased the molecular weight from ca. 600 to ca. $270 \mathrm{kDa}$. These results suggest that $\mathrm{N}$. clavata spider silk proteins might consist of two proteins with a molecular weight of ca. $270 \mathrm{kDa}$ that are crosslinked by disulfide bonds and exist as a dimer of ca. $600 \mathrm{kDa}$.

Polymer Journal (2015) 47, 456-459; doi:10.1038/pj.2015.10; published online 11 March 2015

\section{INTRODUCTION}

Recently, many researchers have become interested in spider silk as a new potential material for textile fibers, sutures ${ }^{1}$ and violin strings ${ }^{2}$ due to its excellent physical properties, such as high mechanical strength, ${ }^{3-7}$ heat resistivity ${ }^{8}$ and ultraviolet (UV) resistivity. ${ }^{9-12}$ The physical properties of spider silk, such as mechanical strength, strongly depend on the molecular weight of the polymers. ${ }^{13,14}$ UV irradiation provides the possibility of increasing the molecular weight ascribed to crosslinks, ${ }^{10}$ whereas UV rays and thermal treatment decompose spider silk ${ }^{9,12,15,16}$ and generally decrease their molecular weight. ${ }^{10,12}$ Thus the determination of the molecular weight of spider silk proteins is important from the viewpoint of evaluating their physical properties. Moreover, such excellent physical properties have led researchers to focus on the mass production of synthetic silk using genetic engineering, which provides silk-like materials of $c a .60 \mathrm{kDa}$ size. ${ }^{17}$ Thus an understanding of the molecular weight of natural spider silk is crucial for evaluating silk prepared by genetic engineering.

Previously, the molecular weight of Nephila clavipes spider silk was measured by electrophoresis and chromatography methods. ${ }^{18-23}$ The molecular weight was determined to be $195-320 \mathrm{kDa}$ in a reduced state, $275-480 \mathrm{kDa}$ in an unreduced state by electrophoresis ${ }^{18,19,23}$ and $520-720 \mathrm{kDa}$ in an unreduced state by chromatography. ${ }^{18,21}$ Thus the values of the molecular weight ranged widely between 195 and 720 $\mathrm{kDa}^{18-23}$ for $N$. clavipes spider silk. The molecular weight values previously reported for $N$. clavipes spider silk $18,19,21,23$ are summarized in Table 1. For comparison, the molecular weight determined for $N$. clavata silk under reduced conditions ${ }^{12}$ is also listed in Table 1 .

Due to the large diversity in molecular weights, a reliable value for the molecular weight of spider silk must be determined. However, problems stemming from marker proteins and the friction of macromolecules render molecular weight determination by electrophoresis challenging. The first problem is related to the large error in the estimated molecular weight when determining a high molecular weight from a calibration curve using electrophoresis, because no markers with a molecular weight $>300 \mathrm{kDa}$ are available. The second problem is related to the large error in the position of the bands, because macromolecules with a high molecular weight of $>300 \mathrm{kDa}$ generate strong friction against the polyacrylamide gel mesh used for electrophoresis measurements.

Here we should consider that the data on the molecular weight of spider silk have been restricted to that for $N$. clavipes determined using a marker protein with a molecular weight of $200 \mathrm{kDa}^{23}$ or $250 \mathrm{kDa} .^{18}$ However, no studies have yet determined the molecular weight of silk from the Nephila clavata spider (Japanese golden web spider), which is a different spider species compared with $N$. clavipes, under unreduced conditions (see Table 1).

In our previous paper, ${ }^{12}$ we determined the molecular weight of $N$. clavata spider silk to be $272 \mathrm{kDa}$ in a reduced state. In that study, the reducing agent may have induced the chemical cleavage of protein bonds. If a reducing agent is not used, the molecular weight of spider silk in a natural state could potentially be determined.

Here we attempted to resolve the two problems described above by using the following procedure. We used a protein marker with a molecular weight of $500 \mathrm{kDa}$ to reduce the error in molecular weight measurement. Currently, no markers with molecular weights $>500 \mathrm{kDa}$ are commercially available for sodium dodecyl sulfate (SDS) polyacrylamide gel electrophoresis (PAGE). We also used a 3\% polyacrylamide gel with a mesh size larger than that of a $5 \%$ polyacrylamide gel ${ }^{12}$ to reduce the error arising from the friction of macromolecules. Finally, no reducing agents were used to avoid the reduction of chemical bonds.

This paper describes the measurements of the molecular weight of $N$. clavata spider silk proteins under an unreduced state; this value was 
Table 1 Molecular weights determined for silk proteins of two types of spiders ( $\boldsymbol{N}$. clavipes and $\boldsymbol{N}$. clavata) using electrophoresis

\begin{tabular}{|c|c|c|c|c|c|}
\hline \multirow[b]{2}{*}{ Species } & \multicolumn{2}{|c|}{ Silk protein } & \multirow[b]{2}{*}{ Sample } & \multirow[b]{2}{*}{ Method } & \multirow[b]{2}{*}{ References } \\
\hline & Reduced & Unreduced & & & \\
\hline \multirow[t]{2}{*}{ N. clavipes } & - & 720 & Gland & Chromatography & 21 \\
\hline & - & 520 & Thread & & \\
\hline N. clavipes & $300-350$ & $550-650$ & Thread & Chromatography & 18 \\
\hline N. clavipes & 195,220 & 275 & $\begin{array}{l}\text { Thread, } \\
\text { gland }\end{array}$ & Electrophoresis & 19 \\
\hline N. clavipes & 220 & 320 & $\begin{array}{l}\text { Thread, } \\
\text { gland }\end{array}$ & Electrophoresis & 23 \\
\hline N. clavipes & $260-320$ & $420-480$ & Thread & Electrophoresis & 18 \\
\hline N. clavata & 272 & - & Thread & Electrophoresis & 12 \\
\hline N. clavata & $?$ & $?$ & Thread & Electrophoresis & $\begin{array}{c}\text { Present study } \\
\text { Molecular } \\
\text { weight/kDa }\end{array}$ \\
\hline
\end{tabular}

determined to be $c a$. $600 \mathrm{kDa}$, which is much larger than that measured under a reduced state.

\section{EXPERIMENTAL PROCEDURE}

Sample preparation

Spider silk was prepared by pulling the material out of the abdomens of mature female N. clavata spiders. Three milligrams of spider silk was dissolved in $0.3 \mathrm{ml}$ of saturated lithium thiocyanate (Wako Pure Chemical Industries, Ltd., Osaka, Japan) aqueous solution. No insoluble precipitates were detected in the silk solution. Next, the lithium thiocyanate contained in the silk solution was exchanged with urea by dialysis to remove excess lithium thiocyanate electrolytes that could interfere with the electrophoresis. After the dialysis, a $0.188 \mathrm{moll}^{-1}$ Tris-HCl (pH 6.8) buffer containing 30\% sucrose (Wako Pure Chemical Industries, Ltd.), 6\% SDS (Wako Pure Chemical Industries, Ltd.), $16.8 \%$ 2-mercaptoethanol (Wako Pure Chemical Industries, Ltd.) and $0.0060 \%$ bromophenol blue (Wako Pure Chemical Industries, Ltd.) was added to the urea-exchanged solution. The ratio of buffer to urea-exchanged solution was 1:2 by volume. Next, the silk solution was incubated for $5 \mathrm{~min}$ at $373 \mathrm{~K}$ to prepare a silk solution sample containing the reductant 2-mercaptoethanol for electrophoresis. SDS is an anionic surfactant that powerfully denatures proteins, and 2-mercaptoethanol cleaves S-S bonds by chemical reduction. ${ }^{24}$ After dialysis, a $0.221 \mathrm{moll}^{-1} \mathrm{Tris}-\mathrm{HCl}$ (pH 6.8) buffer containing $37.5 \%$ sucrose, $7.05 \%$ SDS and $0.0071 \%$ bromophenol blue was added to the other ureaexchanged solution. The ratio of buffer to urea-exchanged solution was $1: 2$ by volume. Thus a silk solution containing no 2-mercaptoethanol was prepared as an unreduced sample for electrophoresis by incubation for $5 \mathrm{~min}$ at $373 \mathrm{~K}$.

\section{Materials and methods for electrophoresis}

Electrophoresis was performed using a 3\% polyacrylamide gel with an NA-1010 (Nihon Eido Co., Tokyo, Japan) instrument. Coomassie Brilliant Blue staining (Quick CBB, Wako Pure Chemical Industries, Ltd.) was used to identify band patterns reflecting the existence of proteins in the polyacrylamide gels. ${ }^{25}$ The intensity of the bands in the polyacrylamide gels was measured using an EPSON GT-F650 scanner (Seiko Epson Co., Nagano, Japan). The retention factor ( $\mathrm{Rf}$ ) was determined from the position of bands relative to the migration distance of the proteins. The molecular weight corresponding to the $\mathrm{Rf}$ value was determined from the calibration curve obtained using three different markers with molecular weights of 251, 279 and $500 \mathrm{kDa}$ (HiMark Prestained High Molecular Weight Protein Standard produced by Invitrogen, Carlsbad, CA, USA).

\section{Progress of chemical reduction}

The chemical reduction progress was evaluated in terms of the reaction time. Silk solutions in the presence of $0.72 \mathrm{moll}^{-1}(5.6 \%)$ of 2-mercaptoethanol

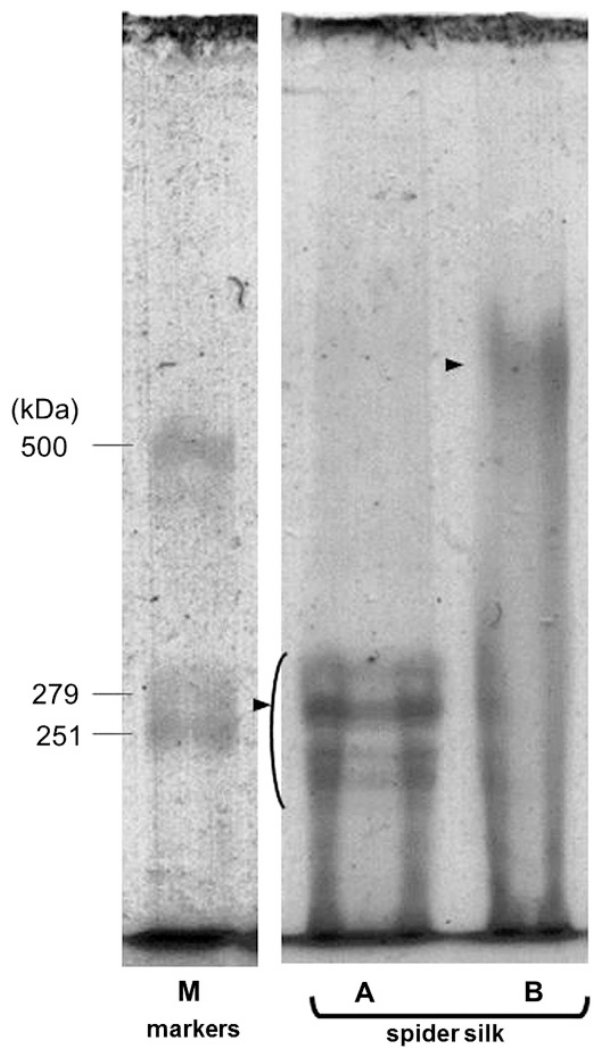

Figure 1 Band patterns for $N$. clavata spider silk proteins and for three different markers in 3\% SDS-PAGE. M: marker. (a) Spider silk solution containing $0.72 \mathrm{moll}^{-1}$ 2-mercaptoethanol, (b): spider silk solution containing no 2-mercaptoethanol.

were prepared by incubation for $27,47,69,90,138,224$ or $303 \mathrm{~s}$. The incubation temperature was maintained at $303 \mathrm{~K}$ to delay the reaction rate. The chemical reaction was stopped by the addition of iodoacetamide (Wako Pure Chemical Industries, Ltd.). The solution at a reaction time of $0 \mathrm{~s}$ corresponded to a sample without 2-mercaptoethanol. Then the electrophoresis measurements were carried out.

The chemical reduction progress was also studied in terms of the amount of reducing agents. Silk solution samples were prepared using the following concentrations of 2-mercaptoethanol: $0,1.0 \times 10^{-5}, 1.0 \times 10^{-4}, 1.0 \times 10^{-3}$, $1.0 \times 10^{-2}, 1.0 \times 10^{-1}, 0.50$, and $1.0 \mathrm{moll}^{-1}$. The incubation step was performed for $10 \mathrm{~min}$ at $373 \mathrm{~K}$ to achieve chemical equilibrium. The electrophoresis measurements were also carried out for each silk solution sample.

\section{RESULTS AND DISCUSSION}

Figure 1 shows the band patterns of 3\% SDS-PAGE for N. clavata spider silk and the molecular weight markers. Here we considered two different cases, with and without the reducing agent. Lane A represents a spider silk solution containing 2-mercaptoethanol as the reducing agent. Lane B represents a spider silk solution containing no 2-mercaptoethanol. For a comparison, Lane $\mathrm{M}$ is the band pattern of three different marker proteins with molecular weights of 251, 279 and $500 \mathrm{kDa}$. Multiple broad bands were observed in Lane A and corresponded to spider silk proteins with molecular weights between 220 and $300 \mathrm{kDa}$. The molecular weight corresponding to the densest band in Lane A was determined to be $c a .270 \mathrm{kDa}$. The molecular weight value determined for Lane A agreed with the value of $c a$. $272 \mathrm{kDa}$ determined for $N$. clavata spider silk reported in our previous paper, ${ }^{12}$ which was larger than the $195-220 \mathrm{kDa}^{19,23}$ reported for silk proteins from the $N$. clavipes spider. However, the value of 
ca. $270 \mathrm{kDa}$ for $N$. clavata silk was in the range of 260 and $320 \mathrm{kDa}$, which was observed for $N$. clavipes using a marker protein with a molecular weight of $200 \mathrm{kDa} .^{18}$

The molecular weights of the proteins corresponding to the broad, dense band in Lane B were found to be between 560 and $660 \mathrm{kDa}$. The median molecular weight in Lane B was ca. $600 \mathrm{kDa}$. The range of $560-660 \mathrm{kDa}$ for $N$. clavata spider silk was much larger than the $420-480 \mathrm{kDa}$ range ${ }^{18}$ reported for $N$. clavipes spider silk measured with no reducing agents by electrophoresis, even though the spider species are very different. Here we noted that the value of $420-480 \mathrm{kDa}^{18}$ reported for $N$. clavipes was determined using markers with molecular weights $<250 \mathrm{kDa}$. However, markers of $250 \mathrm{kDa}$ are too small in comparison with the $420-480 \mathrm{kDa}$ size determined for $N$. clavipes spider silk. A large difference in molecular weight between the silk proteins and the marker is well known to cause a large error in the measured molecular weight value. Therefore, the reported value of $420-480 \mathrm{kDa}^{18}$ for $N$. clavipes likely suffers from large errors. By contrast, the value of $560-660 \mathrm{kDa}$ determined for $N$. clavata in the present study should contain a lower amount of error and serve as a reliable value because the size of the $500 \mathrm{kDa}$ molecular weight marker used here is relatively close to the determined value. The value of $560-660 \mathrm{kDa}$ determined for $N$. clavata spider silk using electrophoresis is comparable with the values of $520 \mathrm{kDa}^{21}$ and $550-650 \mathrm{kDa}^{18}$ determined for $N$. clavipes spider silk using chromatography, even though the spider species and the measurement method used differ greatly.

The ratio of the molecular weight of $N$. clavata silk protein obtained in Lane B (ca. $600 \mathrm{kDa})$ to that in Lane A $(c a .270 \mathrm{kDa})$ was approximately 2.2. This observation suggests that 2-mercaptoethanol exerted a reducing function by cleaving intramolecular and intermolecular crosslinkages, such as disulfide bonds. ${ }^{24}$ These results indicate the possibility that $N$. clavata spider silk proteins with a molecular weight of $c a .600 \mathrm{kDa}$ consist of two proteins with molecular weights of $c a .270 \mathrm{kDa}$ that are crosslinked by a disulfide bond. In all of the reported papers, ${ }^{23,26-28}$ the existence of a disulfide bond has not been directly detected but has been estimated from the amino-acid sequence closely related to the DNA gene alignment of spider silk. Similarly, we can assume the existence of the disulfide

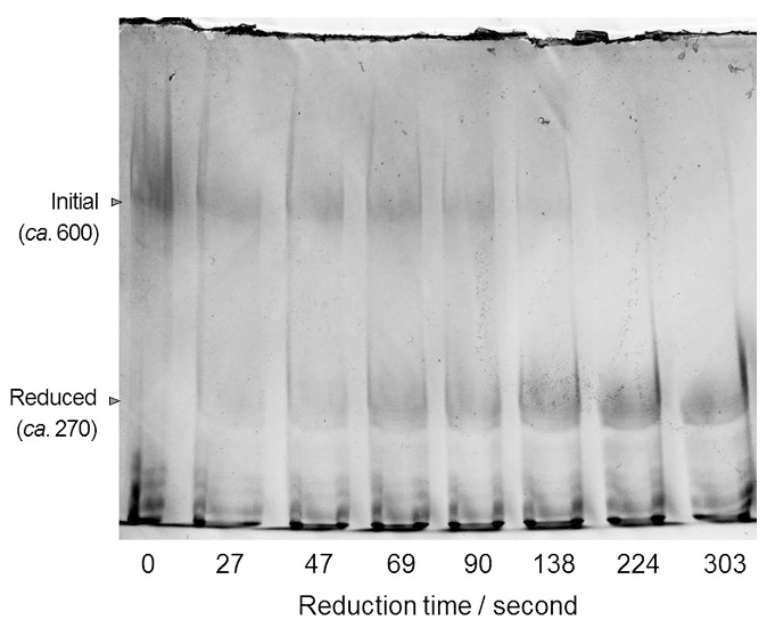

Figure 2 Band patterns for $N$. clavata spider silk protein in 3\% SDS-PAGE with different 2-mercaptoethanol reduction times. The reduction times were 0 (without 2-mercaptoethanol), 27, 47, 69, 90, 138, 224 and $303 \mathrm{~s}$ at $303 \mathrm{~K}$. The concentration of 2 -mercaptoethanol was $0.72 \mathrm{moll}^{-1}$ just after starting the reduction reaction. bond formed between cysteine residues ${ }^{8}$ contained in spider silk proteins from our study.

Next, the effects of reduction time on the spider silk proteins were studied at $303 \mathrm{~K}$ using 2-mercaptoethanol to clarify the reduction process. Figure 2 shows the band patterns for $N$. clavata spider silk in $3 \%$ SDS-PAGE after a reduction of $27,47,69,90,138,224$ or $303 \mathrm{~s}$. A band at $c a .600 \mathrm{kDa}$ was observed at $0 \mathrm{~s}$ just before the addition of 2-mercaptoethanol. The intensity of the bands observed at $c a .600 \mathrm{kDa}$ decreased with reduction time. By contrast, a weak band corresponding to $c a .270 \mathrm{kDa}$ appeared after $27 \mathrm{~s}$. Two bands corresponding to 270 and $600 \mathrm{kDa}$ were distinctly observed after a reduction period of $47 \mathrm{~s}$. However, no bands were observed between 270 and $600 \mathrm{kDa}$ (see Figure 2), indicating that no intermediate compounds were generated during the reduction process.

The chemical reduction shown in Figure 2 was completed within $3 \mathrm{~min}$, even at a low temperature of $303 \mathrm{~K}$ and a fixed reducing agent (2-mercaptoethanol) concentration of $0.72 \mathrm{moll}^{-1}$. Next, spider silk solutions were prepared with different concentrations of 2-mercaptoethanol (between 0 and $1.0 \mathrm{moll}^{-1}$ ) to further evaluate the cleavage process. The chemical reduction procedure was performed by incubation for $10 \mathrm{~min}$ at $373 \mathrm{~K}$ to achieve chemical equilibrium. Figure 3 shows the band patterns for $N$. clavata spider silk in $3 \%$ SDS-PAGE at different concentrations of 2-mercaptoethanol. The intensity of the band corresponding to $c a .600 \mathrm{kDa}$ decreased with increases in the concentration of 2-mercaptoethanol, and the band was not observed at concentrations of $>1.0 \times 10^{-3} \mathrm{moll}^{-1}$. By contrast, bands corresponding to $c a$. $270 \mathrm{kDa}$ appeared at concentrations of $>1.0 \times 10^{-4} \mathrm{moll}^{-1}$ of 2-mercaptoethanol. Although the band intensity at $c a .270 \mathrm{kDa}$ increased with an increase in the concentration of 2-mercaptoethanol, no visible bands were observed in the range of ca. 270 to ca. $600 \mathrm{kDa}$, as shown in Figure 3. The broad bands observed near $270 \mathrm{kDa}$ in Figure 3 agreed with those observed near $270 \mathrm{kDa}$ in Figure 2. The results in Figures 2 and 3 strongly support those of Figure 1. The results suggest that each protein of $c a .270 \mathrm{kDa}$ size is crosslinked by disulfide bonds and constructs a dimer of proteins with a $c a$. $600 \mathrm{kDa}$ size. The disulfide bond between two

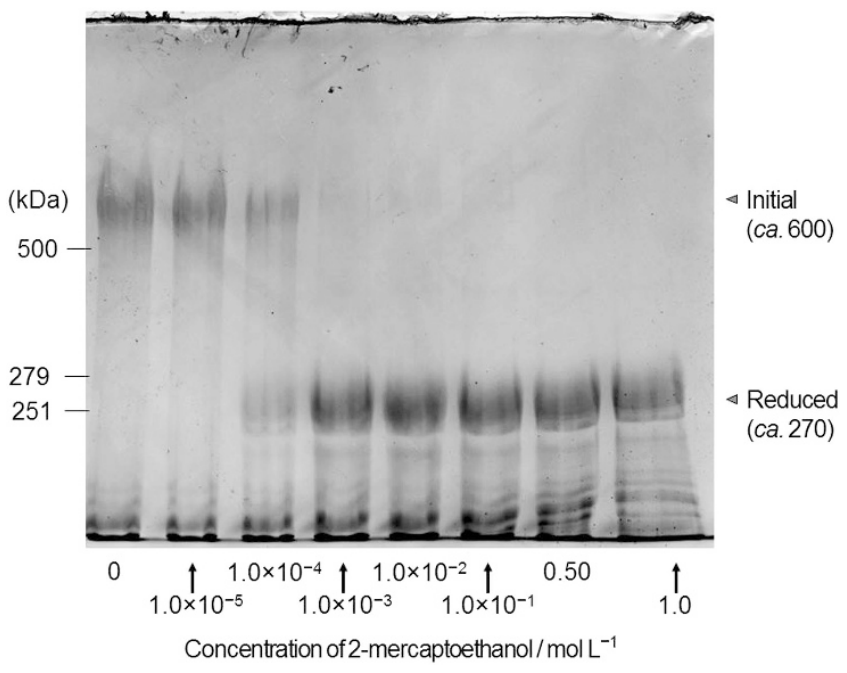

Figure 3 Band patterns for $N$. clavata spider silk protein in 3\% SDS-PAGE at different concentrations of 2-mercaptoethanol. The concentrations of 2-mercaptoethanol used were $0,1.0 \times 10^{-5}, 1.0 \times 10^{-4}, 1.0 \times 10^{-3}$, $1.0 \times 10^{-2}, 1.0 \times 10^{-1}, 0.50$ and $1.0 \mathrm{~mol} \mathrm{I}^{-1}$. 
spider silk proteins is generally formed by the oxidation of cysteine residues. ${ }^{8}$

These results indicate that the cleavage of the disulfide bonds strongly depends on the reaction time and the concentration of the reductant. By contrast, the possibility of a chemical association between the two proteins can be ruled out due to the high molecular weight of $c a .600 \mathrm{kDa}$ for $N$. clavata spider silk, as no bands at $c a$. $270 \mathrm{kDa}$ were observed in SDS-PAGE, even for a diluted solution of proteins without 2-mercaptoethanol.

\section{CONCLUSION}

The molecular weight of $N$. clavata spider silk was found to be ca. $600 \mathrm{kDa}$ in the unreduced state by electrophoresis using a marker protein with a molecular weight of $500 \mathrm{kDa}$, even though the size of reduced $N$. clavata spider silk protein was determined to be $272 \mathrm{kDa}$ in a previous paper. ${ }^{12}$ Such a large difference in the molecular weight is ascribed to the use of 2-mercaptoethanol as a reducing agent. This finding suggests that $N$. clavata spider silk protein roughly consists of two proteins with molecular weights of $c a .270 \mathrm{kDa}$ that are crosslinked by disulfide bonds. However, the value of $c a$. $600 \mathrm{kDa}$ or of $560-660 \mathrm{kDa}$ is not twice the value of $c a .270 \mathrm{kDa}$. Therefore, the proteins of $c a$. $600 \mathrm{kDa}$ or $560-660 \mathrm{kDa}$ size may potentially be modified by small amounts of glucides or phosphates. In such a case, the apparent molecular weight may differ slightly from the actual molecular weight of the intrinsic protein. In the near future, these issues will be resolved at the molecular level.

\section{ACKNOWLEDGEMENTS}

We thank Dr Keizo Yamamoto of Nara Medical University for his advice on the electrophoresis measurements and also Professor Hiromi Sakai of Nara Medical University for his supporting experiments.

1 Kuhbier, J. W., Reimers, K., Kasper, C., Allmeling, C., Hillmer, A., Menger, B., Vogt, P. M. \& Radtke, C. First investigation of spider silk as a braided microsurgical suture. J. Biomed. Mat. Res. Pt. B Appl. Biomat. 97, 381-387 (2011).

2 Osaki, S. Spider silk violin strings with a unique packing structure generate a soft and profound timbre. Phys. Rev. Lett. 108, 154301-154305 (2012).

3 Work, R. W. \& Morosoff, N. S. A physico-chemical study of the supercontraction of spider major ampulate silk fibers. Tex. Res. J. 52, 349-356 (1982).

4 Gosline, J. M., Denny, M. W. \& DeMond, M. E. Spider silk as rubber. Nature 309, 551-552 (1984)
5 Vollrath, F. Biology of spider silk. Int. J. Biol. Macromol. 24, 81-88 (1999).

6 Osaki, S. Spider silk as mechanical lifeline. Nature 384, 419-419 (1996).

7 Osaki, S. \& Ishikawa, R. Determination of elastic modulus of spider's silks. Polym. J. 34, 25-29 (2002)

8 Osaki, S. Thermal properties of spider's thread. Acta Arachnol. 7, 69-75 (1989).

9 Osaki, S., Yamamoto, K., Kajiwara, A. \& Murata, M. Evaluation of the resistance of spider silk to ultraviolet irradiation. Polym. J. 36, 623-627 (2004).

10 Osaki, S. Ultraviolet rays mechanically strengthen spider's silk. Polym. J. 36, 657-660 (2004).

11 Osaki, S. \& Osaki, M. Evolution of spiders from nocturnal to diurnal gave spider silks mechanical resistance against UV -irradiation. Polym. J. 43, 200-204 (2011).

12 Matsuhira, T., Yamamoto, K. \& Osaki, S. Effects of UV irradiation on the molecular weight of spider silk. Polym. J. 45, 1167-1169 (2013).

13 Marshall, I. \& Todd, A. The thermal degradation of polyethylene terephthalate. Trans. Faraday Soc. 49, 67-78 (1953).

14 Yokota, R. Mechanical properties: Increase in mechanical properties ascribed to high polymerization. Kobunshi (in Japanese) 39, 371 (1990).

15 Osaki, S. Aging of spider silks. Acta Arachnol. 43, 1-4 (1994).

16 Osaki, S. Effects of ultraviolet rays and temperature on spider silks. Acta Arachnol. 46, 1-4 (1997).

17 Lazaris, A., Arcidiacono, S., Huang, Y., Zhou, J-F., Duguay, F., Chretien, N., Welsh, E. A., Soares, J. W. \& Karatzas, C. Spider silk fibers spun from soluble recombinant silk produced in mammalian cells. Science 295, 472-476 (2002).

18 Sponner, A., Schlott, B., Vollrath, F., Unger, E., Grosse, F. \& Weisshart, K. Characterization of the protein components of Nephila clavipes dragline silk. Biochemistry 44, 4727-4736 (2005).

19 Mello, C. M., Senecal, K., Yeung, B., Vouros, P. \& Kaplan, D. in Silk Polymers Material Science and Biotechnology (eds Kaplan D., Adams W. W., Farmer B., Viney C.) 67-79 (American Chemical Society, Washington, USA, 1994).

20 Hakimi, O., Knight, D. P., Vollrath, F. \& Vadgama, P. Spider and mulberry silkworm silks as compatible biomaterials. Compos. Pt. B Eng. 38, 324-337 (2007).

21 Jackson, C. \& O'Brien, J. P. Molecular weight distribution of Nephila clavipes dragline silk. Macromolecules 28, 5975-5977 (1995).

22 Vollrath, F. \& Knight, D. P. Liquid crystalline spinning of spider silk. Nature 410 541-548 (2001)

23 Sponner, A., Unger, E., Grosse, F. \& Weisshart, K. Conserved C-termini of spidroins are secreted by the major ampullate glands and retained in the silk thread. Biomacromolecules 5, 840-845 (2004).

24 Aitken, C. E., Marshall, R. A. \& Puglisi, J. D. An oxygen scavenging system for improvement of dye stability in single molecule fluorescence experiments. Biophys. J. 94, 1826-1835 (2008).

25 Laemmli, U. K. Cleavage of structural proteins during the assembly of the head of bacteriophage T4. Nature 227, 680-685 (1970).

26 Ittah, S., Michaeli, A., Goldblum, A. \& Gat, U. A model for the structure of the C-terminal domain of dragline spider silk and the role of its conserved cysteine. Biomacromolecules 8, 2768-2773 (2007).

27 Hedhammar, M., Rising, A., Grip, S., Martinez, A. S., Nordling, K., Casals, C., Stark, M. \& Johansson, J. Structural properties of nonrepetitive and repetitive parts of major ampullate Spidroin 1 from Euprosthenops australis: implications for fiber formation. Biochemistry 47, 3407-3417 (2008).

28 Sponner, A. Vater, W., Rommerskirch, W. Vollrath, F. Unger, E., Gross, F. \& Weisshart, K. The conserved C-termini contribute to the properties of spider silk fibroins. Biochem. Biophys. Res. Commun. 338, 897-902 (2005). 